\title{
Correction to: Development and application of state-dependent fractional plasticity in modeling the non-associated behavior of granular aggregates ${ }^{\star \star}$
}

\author{
Yifei Sun $^{1 \star} \quad$ Shunxiang Song $^{2} \quad$ Yang Xiao $^{3} \quad$ Jiancheng Zhang $^{4}$ \\ $\left({ }^{1}\right.$ Key Laboratory of Ministry of Education for Geomechanics and Embankment Engineering, Geotechnical \\ Engineering Research Center of Jiangsu Province, Hohai University, Nanjing 210098, China) \\ $\left({ }^{2}\right.$ College of Civil and Transportation Engineering, Hohai University, Nanjing 210098, China) \\ $\left({ }^{3}\right.$ State Key Laboratory of Coal Mine Disaster Dynamics and Control, School of Civil Engineering, Chongqing \\ University, Chongqing 400450, China) \\ $\left({ }^{4}\right.$ School of Naval Architecture and Civil Engineering, Jiangsu University of Science and Technology, Jiangsu \\ 215600, China)
}

published online 31 March 2021

(c) The Chinese Society of Theoretical and Applied Mechanics 2021

Correction to: Acta Mech. Solida Sin. 30, 507-519 (2017) https://doi.org/10.1016/j.camss.2017.09.002

The original equation in the text below Eq. (20) is $h_{0}=\left(h_{1}+h_{2} \psi_{0}\right)$ which needs to be corrected as $h_{0}=\left(h_{1}-h_{2} \psi_{0}\right)$.

\footnotetext{
* Corresponding author. E-mail: sunny@hhu.edu.cn

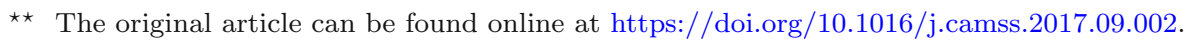

